\title{
Managerial Compensation under Privately-Observed Hedging
}

Liu, Qi and Bo Sun

Please cite paper as:

Liu, Qi and Bo Sun (2016). Managerial Compensation under

Privately-Observed Hedging 1160.

http://dx.doi.org/10.17016/IFDP.2016.1160

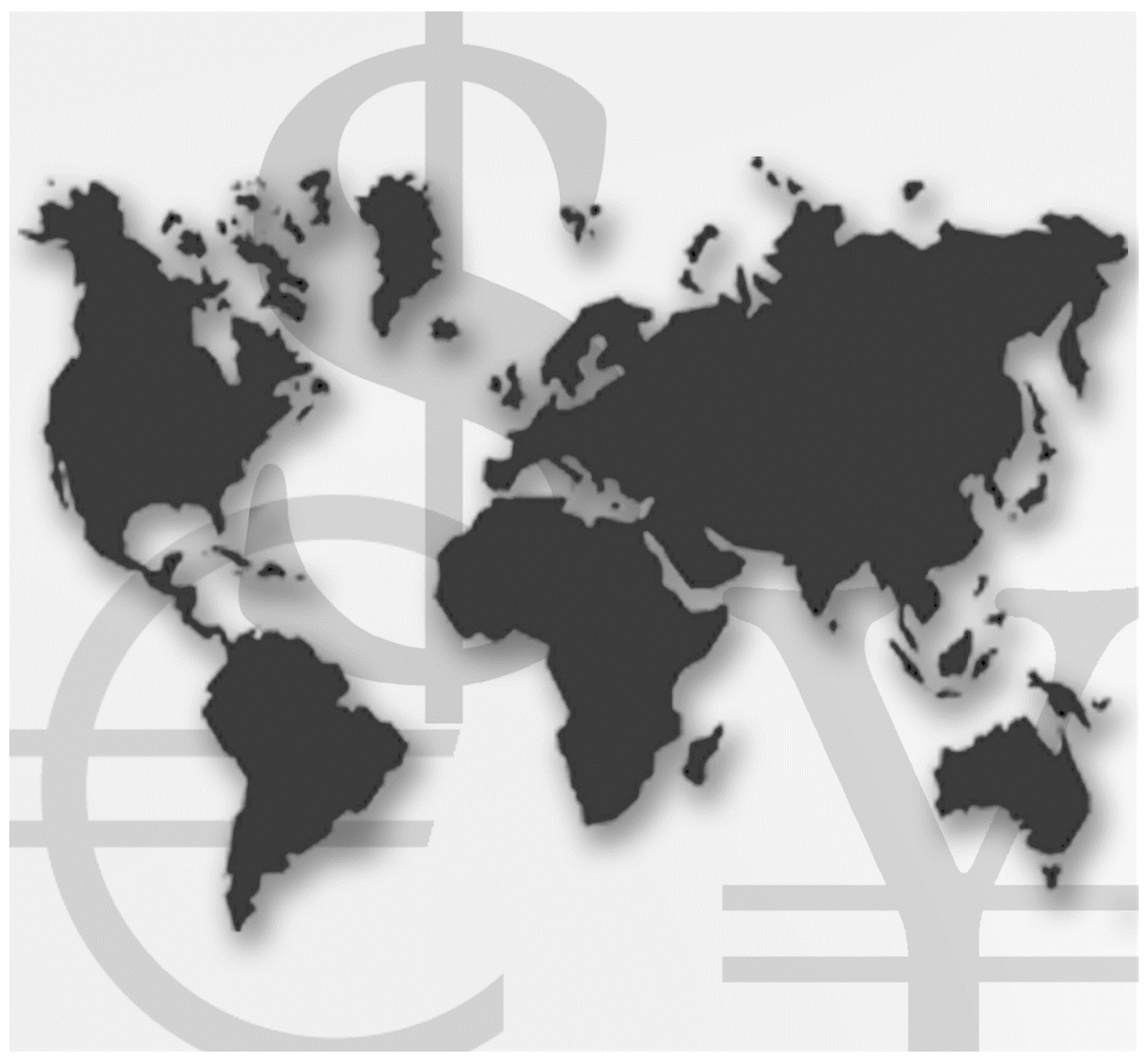

\section{International Finance Discussion Papers}

Board of Governors of the Federal Reserve System

Number 1160

March 2016 
Board of Governors of the Federal Reserve System

International Finance Discussion Papers

Number 1160

March 2016

\title{
Managerial Compensation under Privately-Observed Hedging
}

\author{
Qi Liu and Bo Sun
}

NOTE: International Finance Discussion Papers are preliminary materials circulated to stimulate discussion and critical comment. References to International Finance Discussion Papers (other than an acknowledgment that the writer has had access to unpublished material) should be cleared with the author or authors. Recent IFDPs are available on the Web at www.federalreserve.gov/pubs/ifdp/. This paper can be downloaded without charge from the Social Science Research Network electronic library at www.ssrn.com. 


\title{
Managerial Compensation under Privately-Observed Hedging*
}

\author{
Qi Liu \\ Peking University \\ qiliu@gsm.pku.edu.cn
}

\author{
Bo Sun \\ Federal Reserve Board \\ bo.sun@frb.gov
}

\begin{abstract}
This paper studies how private information in hedging outcomes affects the design of managerial compensation when hedging instruments serve as a double-edged sword in that they may be used for both corporate hedging and earnings management. On the one hand, financial vehicles can offer customized contracts that are closely tailored to manage specific risk and improve hedging efficiency. On the other hand, involvement in hedging may give rise to manipulation through misstatement of the value estimates. We show that the use of privately-observed hedging may actually require greater pay-for-performance in managerial compensation. The cross-sectional variations in managerial compensation lend support to our model.
\end{abstract}

JEL classification: D82, D86, G38, J31.

Keywords: Managerial compensation, Corporate hedging

\footnotetext{
${ }^{*}$ We gratefully acknowledge Joao Gomes (the editor) and an anonymous referee for their comments. One of the authors is a staff economist in the Division of International Finance, Board of Governors of the Federal Reserve System, Washington, D.C. 20551 U.S.A. The views in this paper are solely the responsibility of the authors and should not be interpreted as reflecting the views of the Board of Governors of the Federal Reserve System or of any other person associated with the Federal Reserve System.
} 


\section{Introduction}

Firms use various financial vehicles to hedge against changes in prices or against events such as potential defaults on debt. Because of private information involved in the valuation of many hedging vehicles, hedging also provides executives with the potential to manipulate earnings: Some executives have used derivatives to conceal losses, hide debt, and inflate the value of troubled businesses, as demonstrated in the cases of Fannie Mae, Freddie Mac, and AIG. ${ }^{1}$ To study the contracting implications of the use of privately-observed hedging, we study a model where financial vehicles can be used to hedge the firm's risk exposure as well as facilitate performance manipulation.

Shareholders in our model view financial vehicles as a double-edged sword in that they may be used both for effective hedging and performance manipulation. On the one hand, these instruments can be closely tailored to manage specific risk exposures and therefore enhance firm value. On the other hand, there is a lack of transparency in price discovery and valuation of these hedges, especially because trades can occur in private, creating opportunities for managerial manipulation through misstating the value estimates. ${ }^{2}$ Manipulation may lead to excessive managerial compensation that is unjustified by the underlying profitability.

We show that the use of hedging vehicles requires executive pay to be more responsive to reported performance. Because of hedging vehicles' two functions - both their legitimate function to hedge and their potential use in overstating performance - these instruments serve as insurance for managers against a low compensation payoff. To induce productive effort put forth by managers, the use of privately-observed hedging may actually call for a

\footnotetext{
${ }^{1}$ The SEC determined in 2004 that Fannie Mae and Freddie Mac overstated earnings by incorrectly accounting for various derivative instruments. In the run-up to the 2008 crisis, Freddie Mac and Fannie Mae overstated the value of their portfolios backed by mortgage-backed securities, which enabled the companies to overstate the value of their capital reserves and business worth, veiling substantial build-up of systemic risk.

${ }^{2}$ The over-the-counter derivative market, for example, has been largely unregulated with respect to disclosure of information between the contracting parties. Surveys show that while traders may be in close agreement on the value of actively traded derivatives, their view may be wide apart on less liquid securities, making derivatives easy targets to be misused for manipulation.
} 
higher-powered compensation.

Our baseline contracting model takes the degree of hedging as given and studies its implications for managerial pay-for-performance. However, as opposed to those commonly cited rationales for corporate hedging from shareholders' perspective, it may be the incentives of managers that drive hedging policies. We extend our model to allow the managers to choose the extent of hedging. We show that incentive pay and hedging usage are positively associated, as they are influenced by common determinants in the same manner.

Our paper is motivated by empirical studies on hedging and executive pay. Adkins, Carter, and Simpson (2007) show that greater equity holdings and larger cash bonuses by bank managers are associated with a greater probability of hedging. Geczy, Minton, and Schrand (2007) find that firms for which speculation (on interest rates, exchange rates, etc.) is a core business activity tend to use incentive-aligning compensation for their managers. Chernenko and Faulkender (2011) show that firms' use of interest rate swaps to manipulate earnings coincides with higher pay-performance sensitivities in their executive compensation. The literature has interpreted the association as compensation creating incentives to use hedging vehicles. Our explanation for the association, that is, the use of hedging calls for more incentive pay, is different, but the two mechanisms may co-exist.

In the contracting literature with manipulation, Nan (2008) theoretically shows that earnings management by accounting accruals and derivative use are substitutes in smoothing earnings. Our focus on costly manipulation in an agency model has antecedents in Lacker and Weinberg (1989), which examines optimal contracts under costly state falsification and investigates the main properties of optimal no-falsification contracts. Taking a different view, Goldman and Slezak (2006) and Crocker and Slemrod (2007) consider settings in which manipulation actually arises in the equilibrium, and yet the firm's performance is adjusted to fully correct for the bias in the manipulated reports. In our problem, however, the principal faces uncertainty over whether hedging instruments can be used for manipulation, and therefore cannot perfectly gauge the true state of the firm. ${ }^{3}$

\footnotetext{
${ }^{3}$ Sun (2014) analyzes a model where manipulation is also not fully unravelled in equilibrium, which does
} 
The rest of the paper proceeds as follows. Section 2 discusses how hedging instruments may be used for manipulation. Section 3 lays out the principal-agent model and characterizes the optimal contract. Section 4 extends the model to allow managers to choose derivative holdings. Section 5 concludes. The proofs are in the appendix.

\section{The use of hedging vehicles for manipulation}

Various financial vehicles such as derivatives have historically proven themselves as effective instruments for both hedging and speculative purposes. The creation and trading of hedging vehicles have enabled improved risk-sharing and corporate growth around the globe that would not otherwise have been possible. The role of hedging instruments in boosting performance began to gain increased attention only in the recent years: a number of companies, such as Freddie Mac, Fannie Mae and AIG, used derivatives to conceal losses, hide debt, and inflate the value of troubled businesses. Hedging instruments have a complex accounting treatment, and the involvement and timing of these instruments, such as OTC derivatives, are especially subject to managerial discretion, making them easy targets to be misused by management for personal benefits. Surveys show that while traders may be in close agreement on the value of actively traded hedging vehicles, their view may be wide apart on less liquid securities. This can lead to situations where similar financial instruments are valued at very different prices in different companies. Accounting statements may be of little help in detailing how hedging instruments are used and in assessing the overall risk of the portfolio without an adequate accompanying explanation of the use of these hedging instruments.

A few recent high-profile accounting scandals highlight the significance of the issue. For example, the U.S. Securities and Exchange Commission determined in 2004 that Fannie Mae avoided measuring and recording in its income statement the difference between the

change in the value of its swaps and the change in the value of the items being hedged by the swaps, as required by FAS 133 (accounting rules for derivative instruments and not study the use of hedging instruments that is at the heart of our analysis. 
hedge activities). ${ }^{4}$ Fannie Mae acknowledged that correcting its derivatives accounting would result in a reduction in reported income of about $\$ 10.8$ billion for the years 2001-2004. ${ }^{5}$ Similarly, the SEC alleged that Freddie Mac engaged in an accounting fraud from 2000 to 2004, and the manipulation of earnings occurred by incorrectly accounting for various derivative instruments of the firm as well as manipulating the accounting for loan origination costs and reserves for losses. ${ }^{6}$ Both cases impacted executive compensation during periods of fraudulent accounting and resulted in multi-million dollar fines upon revelation as part of the settlement with the government.

In the run-up to the recent crisis in 2008-2009, Freddie Mac and Fannie Mae again made decisions related to derivatives valuations that, while not necessarily in violation of accounting rules, had the effect of overstating the companies' capital resources and financial stability. They pushed losses into the future by sharply curtailing their repurchases of soured mortgages out of the securitizations they guaranteed. Freddie Mac's portfolio contained many securities backed by subprime loans made to the riskiest borrowers, but the company did not write down the value of many of those loans to reflect drops in market prices as required to comply with "mark-to-market" accounting rules. ${ }^{7}$ These accounting tactics enabled Freddie Mac, and to a lesser degree, Fannie Mae, to overstate the value of their capital reserves and business worth, veiling substantial build-up of systemic risk.

There is a growing literature suggesting that managers of a broad cross-section of firms make accounting and risk management decisions jointly. Barton (2001) provides evidence

\footnotetext{
4 "Accounting Irregularities at Fannie Mae," by SEC Chairman Christopher Cox, before the U.S. Senate Committee on Banking, Housing and Urban Affairs.

5 "Accounting Problems at Fannie Mae" by Mark Jickling, Congressional Research Service Report for Congress.

${ }^{6}$ See the SEC Litigation Release No. 20304.

${ }^{7}$ Freddie Mac and Fannie Mae also inflated their financial positions by relying on deferred-tax assets — credits accumulated over the years that can be used to offset future profits. Fannie included deferred tax assets in its regulatory capital measure. While most of these assets were generated because Fannie suffered massive losses on its derivatives, they are an offset to future taxes Fannie might owe. Fannie maintained that its worth was increased by $\$ 36$ billion through such credits, and Freddie argued that it had a $\$ 28$ billion benefit. But such credits have no value unless the companies generate profits, which both companies failed to achieve in 2007-2009. Moreover, even when the companies had soaring profits, such credits often could not be used because the companies were already able to offset taxes with other credits for affordable housing.
} 
that firms use hedging instruments to keep earnings consistent with forecasts (i.e. income smoothing). Empirical research also shows that firms use interest rate derivatives to speculate on movements in interest rates and to manipulate earnings (Faulkender (2005) and Geczy, Minton, and Schrand (2007)). Chernenko and Faulkender (2011) specifically test whether managers time the term structure to manipulate earnings by interacting the term spread with various measures of earnings management. They find that firms alter the interest rate exposure of the firm's debt through the use of interest rate swaps to meet their earnings forecast which they would otherwise miss. They also find that changes in interest rate exposure of outstanding debt are significantly more sensitive to the term structure for those firm-years in which increases in the amount of floating rate debt used by the firm would enable the firm to meet its consensus financial analysts' forecast, relative to those for which such a change would not alter their ability to meet consensus analysts' forecast. These empirical results highlight the role of financial reporting underlying the use of hedging instruments, which is the key premise our paper builds upon.

\section{Contracting with privately-observed hedging}

\subsection{Assumptions}

A risk-neutral principal (shareholders) hires a risk-averse agent (manager) for one period. The manager's utility function is denoted by $u(\cdot)$, where $u(0)=0, u^{\prime}(\cdot)>0$, and $u^{\prime \prime}(\cdot) \leq 0$. The firm's earnings are stochastic and influenced by the manager's effort. The unobserved effort level of the manager, $e$, can take two values, low $(l)$ and high $(h)$, that is, $e \in\{l, h\}$ where $l<h$. The manager incurs disutility from exerting effort, denoted by the cost function $a(e)$. In particular, high effort is associated with a cost of $a(h)=c$, while low effort involves no cost: $a(l)=0$. Earnings $y$ take two possible values, $y \in\{L, H\}$, where $L<H$. Let $p_{e}$ be the probability that earnings are equal to $H$ when the effort is $e$, where $e \in\{l, h\}$ with $p_{h}>p_{l}$.

The timeline of Figure 1 chronicles the sequence of events in the model. After the manager 
exerts effort, a hedging opportunity stochastically realizes. With probability $1-\theta$, there is no opportunity to hedge. With probability $\theta$, a hedging opportunity arrives: The hedge has zero payoff if earnings are high and may deliver value, which would be privately observed by the manager, if earnings are low (that is, to hedge). With the hedging opportunity, the payoff on the hedge follows the distribution below:

$$
\text { Hedging payoff }= \begin{cases}H-L & \text { with probability } q \\ 0 & \text { with probability }(1-q)\end{cases}
$$

That is, with probability $q$, the payoff on the hedge can bring earnings from low $(L)$ to high $(H)$; with probability $(1-q)$, the payoff on the hedge is insufficient to cover the earnings shortfall and is assumed to be zero for simplicity. In the latter case, manipulation may occur. That is, the value estimate of the hedge can be intentionally manipulated by the manager (to be $H-L$ ) to falsely report high earnings. ${ }^{8}$ We assume that compensation cannot be made contingent on the realization of hedging opportunity.

We interpret $\theta$ as the probability of having an opportunity to hedge and $q$ as the probability of successful hedging (given the hedging opportunity). The realization of the hedging opportunity is publicly observable $;^{9}$ but the outcome of actual success or failure of hedging is only privately observed by the manager. A larger probability of having a hedging opportunity $(\theta)$ increases both the likelihood of successful hedging (i.e., $\theta q$ ) and the likelihood of manipulation (i.e., $\theta(1-q))$.

The probabilistic hedging success (that occurs with probability $q$ ) captures the ambiguity in valuation, which renders manipulation possible. That is, the stochastic hedging payoff breaks down a direct mapping between reported earnings and true earnings - the payoff from hedging remains the manager's private information, and the principal can make inferences about true earnings but cannot perfectly gauge the value.

If the manager manipulates earnings by overstating the value of the hedge, the manager incurs a personal cost, denoted by $\phi(\cdot)$. When the manager overstates earnings by inflating

\footnotetext{
${ }^{8}$ Actual hedging can involve hedging costs, which can be assumed away if they are paid before the realization of the hedging opportunity.

${ }^{9}$ For example, when the counterparty defaults, the lack of hedging opportunity is publicly observable.
} 
Figure 1: Model Timeline

\begin{tabular}{lllll}
\hline Manager & Hedging & Manager & Earnings & Manager \\
exerts & opportunity & privately & realize, & makes a \\
effort & realizes & learns & privately & report \\
$e \in\{l, h\}$ & with prob $\theta$ & hedging & observed & and is \\
& and is & payoff & by manager & compensated \\
& publicly known & & &
\end{tabular}

the hedging payoff (to be $H-L$ when it is zero), there is a positive cost $\phi(H-L)=\psi>$ 0 . Reporting honestly involves no cost: $\phi(0)=0$. We define that earnings management (manipulation) emerges in this environment if the manager announces high earnings $(H)$ when the actual realization of earnings (combined with the hedge's payoff) is low $(L)$. We can see that opportunities for manipulation, that is, reporting the hedging payoff to be $(H-L)$ when it is actually zero, arise when the following conditions are met: (i) low earnings realize, (ii) the hedging opportunity realizes, and (iii) the payoff on the hedge is zero. As the contract must be designed based on mutually observed variables, compensation must be based on the manager's report.

\subsection{The contracting problem}

The contract between the risk-neutral principal and the risk-averse manager includes a set of wages contingent on the reports, denoted as $w_{i}, i \in\{L, H\}$. Under Assumption 1, the cost of manipulation is sufficiently small that the manager will inflate earnings by overstating the hedging payoff whenever possible.

Lemma 1 There exists a threshold $\hat{\psi}$ such that in the equilibrium, the manager overstates earnings by inflating the hedging payoff when he has the opportunity if $\psi<\hat{\psi}$; and the manager reports truthfully if $\psi>\hat{\psi}$.

Assumption $1 \psi<\hat{\psi}$ holds.

Following the convention, we assume that the difference in expected earnings is large enough that the principal always wants to implement high effort. Thus, the principal's 
objective is to minimize the wage payment to induce high effort. Formally, the optimal contract solves

$$
\begin{array}{rl}
\min _{w_{H}, w_{L}} & E[w \mid h] \\
& =\theta w_{H}+(1-\theta)\left[p_{h} w_{H}+\left(1-p_{h}\right) w_{L}\right]
\end{array}
$$

subject to

$$
\begin{gathered}
(1-\theta)\left[p_{h} u\left(w_{H}\right)+\left(1-p_{h}\right) u\left(w_{L}\right)\right]+\theta q u\left(w_{H}\right)+\theta(1-q)\left[p_{h} u\left(w_{H}\right)+\left(1-p_{h}\right)\left(u\left(w_{H}\right)-\psi\right)\right]-c \\
\geq(1-\theta)\left[p_{l} u\left(w_{H}\right)+\left(1-p_{l}\right) u\left(w_{L}\right)\right]+\theta q u\left(w_{H}\right)+\theta(1-q)\left[p_{l} u\left(w_{H}\right)+\left(1-p_{l}\right)\left(u\left(w_{H}\right)-\psi\right)\right], \quad(I C) \\
w_{H} \geq 0, w_{L} \geq 0 .
\end{gathered}
$$

The objective function is the expected wage payment for the principal to motivate effort. The first term is the expected wage payout when the hedging opportunity realizes, and the second term is the expected wage absent of a hedging opportunity. The first constraint is the incentive constraint for the manager's choice of effort-here, we assume that the principal wants to induce high effort. The second constraint reflects the non-negativity of wages (i.e., limited liability). The participation constraint is always satisfied given $(L L)$, when the manager's outside option is normalized to zero. In equilibrium $w_{L}=0$ and $w_{H}>0$, and we use $w_{H}-w_{L} \equiv w_{H}$ to denote the pay-for-performance in our model.

\subsection{Hedging and incentive pay}

Suppose that $\theta$ becomes positive and greater and thus the manager is more likely to be able to report high earnings, either due to effective hedging or earnings management. The greater discretion to report high earnings in a low state undermines managerial incentive to exert effort under any given compensation schemes. Executive compensation consequently requires more incentive pay to motivate effort.

Proposition 1 Suppose that Assumption 1 holds. Then $w_{H}-w_{L}$ is increasing in $\theta$.

Proposition 1 shows that when hedging is necessary for business operation, shareholders need to provide stronger monetary incentives to overcome the additional managerial incentives to shirk because of opportunities to successfully hedge and manipulate performance. 
However, successful hedging is more appealing (than manipulation) to the manager because it does not incur additional costs. Thus, when $q$ increases, this improved (costless) insurance against low compensation further undermines incentives to work, which, in turn, calls for a stronger-powered compensation to induce managerial effort. Proposition 2 summarizes this result. $^{10}$

Proposition 2 Suppose that Assumption 1 holds. $w_{H}-w_{L}$ is increasing in $q$.

\subsection{Continuous effort choices}

We now extend our model to allow for a continuum of effort. Specifically, here we assume that the manager's effort $(e)$ can take any value over the interval $[l, h]$. We assume that the optimal target effort for the principal is $h$. If the manager exerts an effort level $(e)$, he will incur a cost $a(e)$, where $a(l)=0$ and $a^{\prime}(e)>0$. The firm's future earnings will be high $(H)$ with probability $p(e)$ and will be low $(L)$ with probability $1-p(e)$, where $p^{\prime}(e)>0$. Then incentive constraint becomes

$$
\begin{aligned}
h= & \arg \max _{e}(1-\theta)\left[p(e) u\left(w_{H}\right)+(1-p(e)) u\left(w_{L}\right)\right]+\theta q u\left(w_{H}\right) \\
& +\theta(1-q)\left[p(e) u\left(w_{H}\right)+(1-p(e))\left(u\left(w_{H}\right)-\psi\right)\right]-a(e)
\end{aligned}
$$

It is straightforward to derive that the incentive constraint (IC) is equivalent to $p^{\prime}(h) u\left(w_{H}\right)-$ $p^{\prime}(h) \theta\left[u\left(w_{H}\right)-(1-q) \psi\right]-a^{\prime}(h) \geq 0$. Thus, the optimal $w_{H}$ is expressed as:

$$
u^{-1}\left(\frac{1}{1-\theta}\left[\frac{a^{\prime}(h)}{p^{\prime}(h)}-\theta(1-q) \psi\right]\right) .
$$

We formally state the comparative-static result below.

Lemma 2 In the case of continuous effort $e \in[l, h], w_{H}-w_{L}$ is increasing in $\theta$ and $q$.

\footnotetext{
${ }^{10}$ The intuition for the effect of $\theta$ also includes that for $q$ (illustrated in Proposition 2), because $\theta$ also affects the expected manipulation cost $((1-\theta) q)$, which is overturned by the main intuition illustrated in Proposition 1.
} 


\subsection{Discussion: empirical evidence}

We interpret $\theta$ in our model as the probability of being able to access and purchase hedging instruments. Keeping $q$ constant, Proposition 1 suggests that a higher probability of hedging would require greater incentive pay, which is consistent with the positive association documented in the empirical literature. For example, Adkins, Carter, and Simpson (2007) show that greater equity holdings and larger cash bonuses by bank managers are associated with a greater probability of hedging. Geczy, Minton, and Schrand (2007) also find that firms for which speculation (in interest rates, exchange rates, etc.) is a core business activity tend to use incentive-aligning compensation for their managers.

In addition, a greater probability of hedging $(\theta)$ in our model is associated with both a higher probability of manipulation using hedging vehicles (that is, $\theta(1-q)$ ) and a strongerpowered pay. Chernenko and Faulkender (2011) show that firms' use of interest rate swaps to manipulate earnings coincides with higher pay-performance sensitivities in their executive compensation.

These empirical results have been typically interpreted as incentive pay creating incentives to use hedging instruments. We show a plausible and yet overlooked rationale for the observed association: the use of hedging instruments actually calls for stronger payfor-performance to provide adequate incentives. Our mechanism is different, and the two mechanisms may coexist.

Our model predicts a varying degree of optimal performance pay across firms and industries due to differential involvement in hedging. For example, it is reasonable to believe that financial firms have more opportunities to hedge (i.e., a larger $\theta$ ). All else equal, higher performance-based pay is required in the financial industry to incentivize managerial effort given the intensive use of hedging vehicles. The substantial wedge in pay-for-performance between financial and non-financial companies has attracted increased academic and regulatory attention. Although our model is not intended to justify the level or structure of compensation arrangements in the financial service industry, our model suggests that differential pay 
Figure 2: Model Timeline with endogenous $\theta$

\begin{tabular}{|c|c|c|c|c|}
\hline $\begin{array}{l}\text { Manager } \\
\text { exerts } \\
\text { effort } \\
e \in\{l, h\}\end{array}$ & $\begin{array}{l}\text { Manager } \\
\text { chooses } \\
\theta \in\left\{\theta_{h}, \theta_{l}\right\}\end{array}$ & $\begin{array}{l}\text { Manager } \\
\text { privately } \\
\text { learns } \\
\text { hedging } \\
\text { payoff }\end{array}$ & $\begin{array}{l}\text { Earnings } \\
\text { realize. } \\
\text { Manager } \\
\text { privately } \\
\text { observes } \\
\text { earnings }\end{array}$ & $\begin{array}{l}\text { Manager } \\
\text { makes a } \\
\text { report } \\
\text { and is } \\
\text { compensated }\end{array}$ \\
\hline
\end{tabular}

structure across industries need not necessarily reflect suboptimality.

\section{Extension: endogenize hedging}

It is entirely plausible that the degree of hedging and executive compensation are both determined endogenously. Rogers (2002) points out that the firm's management makes the actual decision to hedge. If managers and owners are separate, agency problems should affect the hedging decisions of the firm. When managers make the decision of hedging to maximize their own financial interest, it is possible that managers may use hedging vehicles in a manner that does not maximize the value of the firm, and it is optimal for shareholders to take this into account when structuring managerial compensation. In this section, we incorporate the endogeneity of hedging decisions in optimal contracting.

We modify the model by letting $\theta$ be the manager's choice. That is, managerial effort in searching and accessing hedging instruments improves the probability of having a hedging opportunity. The model timeline is illustrated in Figure 2. We assume that the manager chooses $\theta$ subject to a quadratic cost of accessing and selecting hedging instruments, denoted by $\frac{1}{2} \gamma \theta^{2}$. Let $\theta_{h}$ and $\theta_{l}$ be the manager's choice of hedging under high and low effort, respectively. Same as in the benchmark model, we also assume that compensation cannot be made contingent on the realization of hedging opportunity.

In this environment, the optimal contract has to control for both incentives to choose hedging and incentives to exert effort. From the principal's perspective, hedging instruments are a double-edged sword in that they enhance firm value by effective hedging, however, they 
also create opportunities for managers to manipulate earnings, which leads to excessive pay unjustified by underlying profitability. In particular, given the amount of hedging usage $(\theta)$, the expected benefit of hedging to the principal is $\left(1-p_{h}\right) \theta q(H-L)$. Meanwhile, hedging leads to possible manipulation and higher managerial compensation, and the expected cost to the principal is $\left(1-p_{h}\right) \theta w_{H}$. Therefore, the principal's problem is

$$
\max _{\theta_{h}, w_{H}}\left(1-p_{h}\right) \theta_{h} q(H-L)-\left(1-p_{h}\right) \theta_{h} w_{H}
$$

subject to the $(I C)$ constraint

$p_{h} u\left(w_{H}\right)+\left(1-p_{h}\right) \theta_{h}\left[u\left(w_{H}\right)-(1-q) \psi\right]-\frac{1}{2} \gamma \theta_{h}^{2}-c \geq p_{l} u\left(w_{H}\right)+\left(1-p_{l}\right) \theta_{l}\left[u\left(w_{H}\right)-(1-q) \psi\right]-\frac{1}{2} \gamma \theta_{l}^{2}$,

where

$$
\begin{aligned}
\theta_{h} & =\arg \max p_{h} u\left(w_{H}\right)+\left(1-p_{h}\right) \theta_{h}\left[u\left(w_{H}\right)-(1-q) \psi\right]-\frac{1}{2} \gamma \theta_{h}^{2}, \\
\theta_{l} & =\arg \max p_{l} u\left(w_{H}\right)+\left(1-p_{l}\right) \theta_{l}\left[u\left(w_{H}\right)-(1-q) \psi\right]-\frac{1}{2} \gamma \theta_{l}^{2} .
\end{aligned}
$$

To get a closed-form solution, we assume that the utility function takes the following form: $u(w)=\frac{w^{1-\lambda}}{1-\lambda}$, where $\lambda$ is the manager's relative risk aversion and $0 \leq \lambda<1$. Here, we also focus on the case in which the difference in high earnings and low earnings is large enough such that high effort is optimal, expressed in Assumption 2.

Assumption $2 \frac{1-\gamma}{2-\gamma} q(H-L) \geq u^{-1}\left(\frac{1+\sqrt{1-4 K\left[\frac{c}{p_{h}-p_{l}}-(1-q) \psi\right]}}{2 K}+(1-q) \psi\right)$. holds, where $K=\frac{1}{\gamma}\left(1-\frac{p_{h}+p_{l}}{2}\right)$.

We characterize the optimal contract and study its properties in the proposition below.

Proposition 3 Suppose that Assumption 2 holds. Then the optimal contract is characterized 


$$
\begin{aligned}
w_{H}-w_{L} & =u^{-1}\left(\frac{1+\sqrt{1-4 K\left[\frac{c}{p_{h}-p_{l}}-(1-q) \psi\right]}}{2 K}+(1-q) \psi\right), \\
\theta_{h} & =\frac{1}{\gamma}\left(1-p_{h}\right)\left[u\left(w_{H}\right)-(1-q) \psi\right],
\end{aligned}
$$

where $K=\frac{1}{\gamma}\left(1-\frac{p_{h}+p_{l}}{2}\right)$. The optimal contract satisfies the following the properties:

(i) $w_{H}-w_{L}$ is increasing in $\psi$ and decreasing in $q$.

(ii) $\theta_{h}$ is increasing in $\psi$ and decreasing in $q$.

When the manager makes both effort and hedging decisions, the downside of providing strong incentive pay is that the manager may choose to hold a substantial amount of hedging instruments, which is a substitute for productive effort in delivering high compensation. As it becomes more personally costly for the manager to manipulate earnings, that is, $\psi$ increases, it reduces incentives to use hedging instruments for manipulation purposes. All else equal, the manager has incentives to avoid the increased manipulation cost that incurred in low states. Now providing high-powered compensation is more effective in incentivizing high effort instead of inducing manipulation through hedging usage, and it is optimal for the principal to increase incentive pay.

The pay-for-performance decreases with the likelihood of effective hedging for a similar reason. When hedging becomes less effective, that is, $q$ decreases, there is less substitutability between hedging usage and productive effort in achieving high earnings. The principal therefore is able to implement high effort more effectively using incentive pay without worrying that it would generate excessive hedging. In this version of our model, both incentive pay and hedging are endogenously determined, and they move in the same direction as the empirical studies suggest. 


\section{Conclusion}

In this paper, we model the shareholder-manager relationship to study the implications of privately-observed hedging for executive compensation. We show that equilibrium payfor-performance actually increases with the use of hedging instrments. To rationalize the observed positive association, it has been argued that a higher-powered compensation incentivizes managers to use more hedging vehicles. We show that as these instruments serve as a substitute for managerial effort in delivering high earnings, through both customized hedging and earnings management, the use of hedging vehicles undermines incentives to exert effort. Greater incentive pay is thus required to provide adequate effort incentives. Our explanation for the observed association is different from the literature, but the two mechanisms may co-exist. 


\section{References}

[1] Adkins, L. C., Carter, D. A. and Simpson, W. G. 2007. "Managerial Incentives and the Use of Foregin-Exchange Derivatives By Banks," Journal of Financial Research, 30, 399-413.

[2] Chernenko S, Faulkender M. 2011. "The Two Sides of Derivatives Usage: Hedging and Speculating with Interest Rate Swaps," Journal of Financial and Quantitative Analysis, $46(6), 1727$.

[3] Crocker, K., Slemrod, J., 2007. "The Economics of Earnings Manipulation and Managerial Compensation," The RAND Journal of Economics, 38, 698-713.

[4] Geczy, C. C, Minton B. A., Schrand, C. M. "Taking a View: Corporate Speculation, Governance, and Compensation," The Journal of Finance, 62(5): 2405-2443.

[5] Goldman, E., Slezak, S.L., 2006. "An Equilibrium Model of Incentive Contracts in the Presence of Information Manipulation," Journal of Financial Economics, 80, 603-626.

[6] Nan, L. 2008. "The Agency Problems of Hedging and Earnings Management," Contemporary Accounting Research, 25, 859-890.

[7] Lacker, J. M. and Weinberg, J. A. (1989). "Optimal contracts under costly state falsification," The Journal of Political Economy, 1345-1363.

[8] Rogers, D. A., (2002). "Does executive portfolio structure affect risk management? CEO risk-taking incentives and corporate derivatives usage," Journal of Banking and Finance, $26,271-295$.

[9] Smith, C.W., Jr., Stulz, R.M., (1985). " The determinants of firms' hedging policies," Journal of Financial and Quantitative Analysis, 20, 391-405.

[10] Sun, B. (2014). "Executive compensation and earnings management under moral hazard," Journal of Economic Dynamics and Control, 41, 276-290. 


\section{Appendix:}

Proof of Lemma 1: From the proof of Proposition 1 below, we can see that $w_{H}=$ $u^{-1}\left(\frac{1}{1-\theta}\left[\frac{c}{p_{h}-p_{l}}-\theta(1-q) \psi\right]\right)$ is decreasing in $\psi$, so there exists a unique cut-off $\hat{\psi}$ that satisfies $u^{-1}\left(\frac{1}{1-\theta}\left[\frac{c}{p_{h}-p_{l}}-\theta(1-q) \hat{\psi}\right]\right)=\hat{\psi}$. Moreover, if $\psi<\hat{\psi}$, then $u\left(w_{H}\right)=$ $\frac{1}{1-\theta}\left[\frac{c}{p_{h}-p_{l}}-\theta(1-q) \psi\right]>\psi$, earnings manipulation will occur; if $\psi>\hat{\psi}$, then $u\left(w_{H}\right)=$ $\frac{1}{1-\theta}\left[\frac{c}{p_{h}-p_{l}}-\theta(1-q) \psi\right]<\psi$, so the manager will report truthfully. Thus, the optimal $w_{H}$ does not depend on $\psi$ in this case.

Proof of Proposition 1 and Proposition 2: Since $w_{L}=0$, it is easy to see that the condition for inducing high effort is

$$
p_{h} u\left(w_{H}\right)+\left(1-p_{h}\right) \theta\left[u\left(w_{H}\right)-(1-q) \psi\right] \geq p_{l} u\left(w_{H}\right)+\left(1-p_{l}\right) \theta\left[u\left(w_{H}\right)-(1-q) \psi\right]+c,
$$

which can be simplified to $u\left(w_{H}\right) \geq \frac{1}{1-\theta}\left[\frac{c}{p_{h}-p_{l}}-\theta(1-q) \psi\right]$. So the optimal solution is

$$
\begin{gathered}
w_{H}=u^{-1}\left(\frac{1}{1-\theta}\left[\frac{c}{p_{h}-p_{l}}-\theta(1-q) \psi\right]\right) . \\
\frac{\partial}{\partial \theta}\left(\frac{1}{1-\theta}\left[\frac{c}{p_{h}-p_{l}}-\theta(1-q) \psi\right]\right)=\frac{1}{1-\theta}\left(u\left(w_{H}\right)-(1-q) \psi\right)>0, \text { because } u\left(w_{H}\right) \geq \psi .
\end{gathered}
$$

So $w_{H}$ is increasing in $\theta$. It is also straightforward to see that $w_{H}$ is increasing in $q$.

Proof of Proposition 3: The (IC) constraint can be simplified to $u\left(w_{H}\right)-\frac{1}{\gamma}\left(1-\frac{p_{h}+p_{l}}{2}\right)\left[u\left(w_{H}\right)-\right.$ $(1-q) \psi]^{2} \geq \frac{c}{p_{h}-p_{l}}$. Let $x=(1-q) \psi$, then it is straight-forward to see that $u\left(w_{H}-\right.$ $\left.w_{L}\right)=\frac{1+\sqrt{1-\frac{4 K c}{p_{h}-p_{l}}+4 K x}}{2 K}+x$ is increasing in $x$. So $w_{H}-w_{L}$ is increasing $x$, and thus is increasing in $\psi$ and decreasing in $q$. Similarly, it is directly to calculate that $\theta_{h}=\frac{1}{\gamma}\left(1-p_{h}\right) \frac{1+\sqrt{1-\frac{4 K c}{p_{h}-p_{l}}+4 K x}}{2 K}$ is increasing in $x$, and thus is increasing in $\psi$ and decreasing in $q$. 